\title{
Diverse Thalamocortical Short-Term Plasticity Elicited by Ongoing Stimulation
}

\author{
Marta Díaz-Quesada, ${ }^{1 \star}$ Francisco J. Martini, ${ }^{1 \star}$ Giovanni Ferrati, ${ }^{1}$ Ingrid Bureau, ${ }^{2}$ and Miguel Maravall ${ }^{1}$ \\ ${ }^{1}$ Instituto de Neurociencias de Alicante, Universidad Miguel Hernández de Elche-Consejo Superior de Investigaciones Científicas, Campus de San Juan, \\ 03550 Sant Joan d'Alacant, Spain, and 'INSERM U901, Institut de Neurobiologie de la Méditerranée, 13273 Marseille, France
}

To produce sensation, neuronal pathways must transmit and process stimulus patterns that unfold over time. This behavior is determined by short-term synaptic plasticity (STP), which shapes the temporal filtering properties of synapses in a pathway. We explored STP variability across thalamocortical (TC) synapses, measuring whole-cell responses to stimulation of TC fibers in layer 4 neurons of mouse barrel cortex in vitro. As expected, STP during stimulation from rest was dominated by depression. However, STP during ongoing stimulation was strikingly diverse across TC connections. Diversity took the form of variable tuning to the latest interstimulus interval: some connections responded weakly to shorter intervals, while other connections were facilitated. These behaviors did not cluster into categories but formed a continuum. Diverse tuning did not require disynaptic inhibition. Hence, monosynaptic excitatory lemniscal TC connections onto layer 4 do not behave uniformly during ongoing stimulation. Each connection responds differentially to particular stimulation intervals, enriching the ability of the pathway to convey complex, temporally fluctuating information.

\section{Introduction}

We experience the world in both space and time. In the rodent somatosensory system, the spatial relationship between individual whiskers is preserved in a series of well studied topographical maps that occur at each stage of the projection from the periphery to the cortex (Petersen, 2007). However, whisker-mediated discrimination of tactile stimuli relies on temporal as well as spatial cues. During sensory exploration, the stimulus features that can be exploited to permit detection and identification are translated into the form of an intermittent temporal pattern of fluctuations in whisker motion. For example, whisker motion generated during natural exploration of textures is characterized by intermittent "stick-slip" events arriving at irregular intervals (Arabzadeh et al., 2005; Lottem and Azouz, 2008, 2009; Ritt et al., 2008; Wolfe

\section{Received June 9, 2013; revised 0ct. 18, 2013; accepted Nov. 19, 2013.}

Author contributions: M.D.-Q., F.J.M., and M.M. designed research; M.D.-Q., F.J.M., G.F., and I.B. performed research; F.J.M. and M.M. contributed unpublished reagents/analytic tools; M.D.-Q., F.J.M., G.F., and M.M. analyzed data; F.J.M. and M.M. wrote the paper.

This research was supported by grants from the Spanish Ministry of Science and Innovation (BFU2008-03017/BFI and BFU2011-23049, cofunded by the European Regional Development Fund; Consolider Program CSD200700023); the Valencia Regional Government (ACOMP2010/199 and PROMETE0/2011/086); the Spanish National Research Council (CSIC); and the European Commission FP7 (IRG 200405 and ITN Marie Curie SyMBaD, grant agreement 238608). M.D.-Q. was supported by an I3P fellowship from the CSIC. We thank M.C. Castellanos for help with statistics; A. Fairén and C. Gil for advice on slice orientation; A. Valero Paternain for experimental advice; and M.E. Diamond, K.M. Franks, J. Lerma, and R.S. Petersen for critical reading of previous versions of the manuscript.

${ }^{*} M . D .-Q$. and F.J.M. contributed equally to this work.

The authors declare no competing financial interests.

Correspondence should be addressed to Miguel Maravall or Francisco J. Martini, Instituto de Neurociencias de Alicante UMH-CSIC, Campus de San Juan, Apartado 18, 03550 Sant Joan d'Alacant, Spain, E-mail: mmaravall@umh.es or francisco.martini@unibas.ch.

M. Díaz-Quesada's present address: Brain Institute, University of Utah, 36 South Wasatch Drive, Salt Lake City, UT 84112.

F.J. Martini's present address: Biozentrum, University of Basel, Klingelbergstrasse 50/70, 4056 Basel, Switzerland.

DOI:10.1523/JNEUROSCI.2441-13.2014

Copyright $\odot 2014$ the authors $\quad 0270-6474 / 14 / 340515-12 \$ 15.00 / 0$ et al., 2008; Jadhav et al., 2009; Jadhav and Feldman, 2010; Morita et al., 2011). These events can successfully activate neurons throughout the pathway from the whiskers up to the barrel cortex (Arabzadeh et al., 2005; Jadhav et al., 2009; Lottem and Azouz, 2009). Moreover, barrel cortex neurons respond differentially to irregular and regular whisker stimulation (Lak et al., 2008, 2010), indicating that differences in temporal stimulation pattern are read and discriminated centrally.

In the somatosensory, visual and auditory systems, sensory information is transmitted to the cortex via thalamocortical (TC) synapses. Moment-to-moment changes in the size and reliability of these connections, termed short-term synaptic plasticity (STP), shape the dynamics of information flow into the cortex during ongoing stimulation. STP depends on stimulus frequency and therefore endows synapses with particular temporal or spectral filtering properties (Fortune and Rose, 2001; Abbott and Regehr, 2004; Buonomano and Maass, 2009). Specifically, the synapses mediating the principal "driver" pathway between TC neurons and excitatory neurons in layer 4 display STP dominated by strong depression when stimulated from rest (Stratford et al., 1996; Gil et al., 1997, 1999; Chung et al., 2002; Bruno and Sakmann, 2006; Sherman and Guillery, 2006). However, sensory information is typically delivered to the cortex on top of a background of other spontaneous and evoked activity. The degree of TC synaptic depression depends on the level of prior activity (Castro-Alamancos and Oldford, 2002; CastroAlamancos, 2004; Boudreau and Ferster, 2005; Reig et al., 2006), and this may dramatically alter the transfer of information to the cortex.

Here we evaluated the short-term dynamics of different TC connections during ongoing stimulation by recording responses in layer 4 neurons to both regular and irregular stimulation of thalamic fibers. STP during ongoing stimulation was highly het- 
erogeneous across connections, a diversity that could largely be explained by variable tuning to single interstimulus intervals (ISIs). Our data suggest that the population of TC connections from the ventral posterior medial (VPM) thalamic nucleus to layer 4 neurons routes sensory information selectively, with different subgroups of connections responding to different intervals.

\section{Materials and Methods}

Slice preparation. All procedures complied with national and European Union policies for the care and use of animals in research. TC slices (Agmon and Connors, 1991) were obtained from mice between 14 and 25 postnatal days of age, later than the critical period for TC synaptic plasticity (Crair and Malenka, 1995) and the period when sensory responses have been described as facilitating (Borgdorff et al., 2007). C57BL/6 and ICR mouse strains were used; the results were equivalent and were pooled together. Mice were of either sex. Slices (350 $\mu \mathrm{m}$ thickness) were prepared following conventional methods (Díaz-Quesada and Maravall, 2008). Briefly, after killing the animal, the brain was removed and placed in ice-cold cutting solution bubbled with carbogen $\left(95 \% \mathrm{O}_{2}, 5 \% \mathrm{CO}_{2}\right)$ and containing the following (in $\mathrm{mm}$ ): $110 \mathrm{Cl}$ choline, $25 \mathrm{NaHCO}_{3}$, 25 D-glucose, $11.6 \mathrm{Na}$-aspartate, $7 \mathrm{MgSO}_{4}, 3.1$ Na-pyruvate, $2.5 \mathrm{KCl}, 1.25 \mathrm{NaH}_{2} \mathrm{PO}_{4}$, and $0.5 \mathrm{CaCl}_{2}$. The brain was split at the midline, and each hemisphere glued to a custom-made wedge at a slope of $50^{\circ}$. Usually, only one TC slice was obtained from each hemisphere. To verify the origins of TC inputs onto layer 4 neurons in slices at this cutting angle, we conducted a separate set of experiments recording synaptic responses to glutamate uncaging with laser-scanning photostimulation $(n=8)$. This method, which does not stimulate fibers of passage, found that thalamic inputs onto layer 4 neurons originated specifically within the VPM nucleus (Fig. $1 B-D$ ). As a control, we recorded inputs to layer $5 \mathrm{~A}$ neurons and found that they originated within the posteromedial (PoM) complex (data not shown).

Slices were cut on a vibratome (Integraslice 7550M; Campden Instruments) and were transferred to a chamber containing artificial CSF (ACSF) continuously perfused with carbogen. They were then incubated in ACSF at $34^{\circ} \mathrm{C}$ for $\sim 30$ min before recording and then kept at room temperature until used. We used two ACSF solutions. Most results (Figs. $2,3,4,5,6,7,8)$ were collected using a "low-calcium concentration" (low- $\left[\mathrm{Ca}^{2+}\right]$ ) solution containing the following (in $\mathrm{mM}$ ): $127 \mathrm{NaCl}, 25$ $\mathrm{NaHCO}_{3}, 25$ D-glucose, $2.5 \mathrm{KCl}, 1.25 \mathrm{NaH}_{2} \mathrm{PO}_{4}, 2 \mathrm{MgCl}_{2}$, and $1 \mathrm{CaCl}_{2}$. This gave a $\left[\mathrm{Ca}^{2+}\right]$ closer to physiological values than conventional ACSFs for in vitro recording. To examine the effects of $\left[\mathrm{Ca}^{2+}\right]$ on STP diversity (Fig. 6) and allow comparison with other in vitro studies, we also used a solution with the following modified concentrations (in $\mathrm{mM}$ ): 2 $\mathrm{CaCl}_{2}$ and $1 \mathrm{MgCl}_{2}$. All chemicals were obtained from Sigma-Aldrich unless otherwise noted.

Recordings. Patch electrodes were pulled from borosilicate glass (3-6 $\mathrm{M} \Omega$; outer diameter, $1.5 \mathrm{~mm}$; inner diameter, $0.86 \mathrm{~mm}$; Harvard Apparatus and WPI) and were filled with an internal solution containing the following (in $\mathrm{mm}$ ): $130 \mathrm{~K}$-methylsulfonate, $10 \mathrm{Na}$-phosphocreatine, 10 HEPES, $4 \mathrm{MgCl}_{2}, 4 \mathrm{Na}_{2}$-ATP, $3 \mathrm{Na}$-ascorbate, and $0.4 \mathrm{Na}_{2}$-GTP, pH 7.33, 287-303 mOsm. Alexa Fluor 594 (Invitrogen) or DNDS (4,4'-dinitrostilbene-2,2' -disulfonate; Tocris Bioscience) were added to the internal solution in subsets of experiments. Recordings were performed at room temperature $\left(24^{\circ} \mathrm{C}\right)$ or at $32-34^{\circ} \mathrm{C}$.

Neurons were visualized with infrared differential interference contrast optics and patched using whole-cell methods. Recordings were not corrected for liquid junction potential. Neurons were classified according to their response to depolarizing square pulses of $500 \mathrm{~ms}$ duration and increasing intensity. Only neurons with the regular spiking phenotype (McCormick et al., 1985) were included in the analyzed dataset. Input resistance was in the range $150-500 \mathrm{M} \Omega$, and access resistance was $<10 \%$ of input resistance; recordings were discarded if access resistance was unstable or the resting membrane potential drifted by $>10 \mathrm{mV}$. Data were acquired with an Axon Multiclamp 700-B amplifier (Molecular Devices), filtered at $4-10 \mathrm{kHz}$, and sampled at $20 \mathrm{kHz}$ (PCI 6040-E;
A

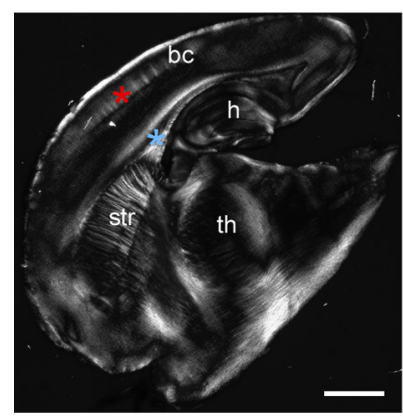

B

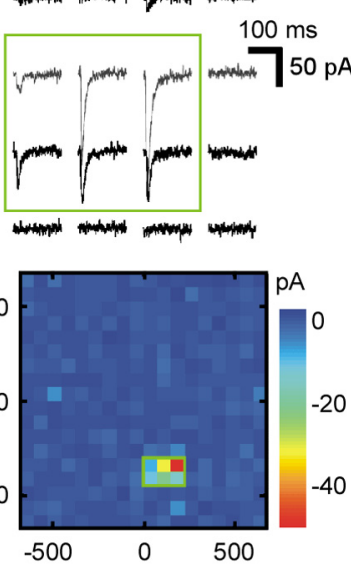

C

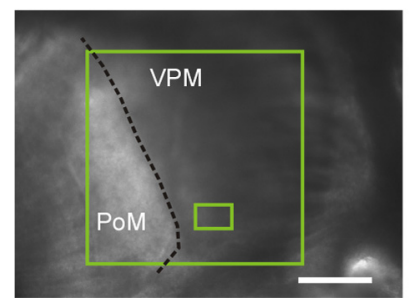

D

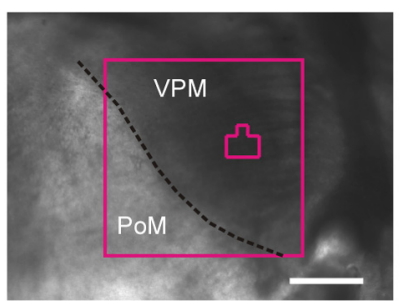

Figure 1. TC slice configuration and the origin of TC inputs to layer 4. $\boldsymbol{A}, \mathrm{TC}$ slice configuration. bc, Barrel cortex; th, thalamus; h, hippocampus; str, striatum. Asterisks indicate typical sites for recording (red) and stimulation (blue). Scale bar, $1 \mathrm{~mm}$. $\boldsymbol{B}$, Top, Mean EPSC responses to laser-scanning photostimulation of 16 sites within a grid placed over the thalamic region of an example slice. Each trace depicts the average response at one stimulation site. The green rectangle demarcates the clearest synaptic inputs. Bottom, Color-coded input map for the full grid (18 $\times 18$ sites); same example slice as in the top panel. The small green rectangle represents the region of origin of the clearest inputs (same as the green rectangle in the top panel). $\boldsymbol{C}$, Thalamic stimulation region and region of origin of clearest inputs relative to VPM and PoM, same example slice as $\boldsymbol{B}$. Large green square depicts full photostimulation grid from $\boldsymbol{B}$, bottom, $1350 \mu \mathrm{m}$ on the side; the small rectangle is the region of origin of clearest inputs, as in $\boldsymbol{B}$. Scale bar, $500 \mu \mathrm{m}$. D. The thalamic stimulation region (large square) and the region of origin of clearest inputs (small polygon) for a layer 4 recording in a different slice. Thalamic inputs to layer 4 neurons originate in VPM. Scale bar, $500 \mu \mathrm{m}$.

National Instruments) under the control of software custom written in Matlab (MathWorks; Pologruto et al., 2003).

Electrical stimulation. TC fibers were stimulated with a Pt-Ir concentric bipolar electrode (FHC; outer pole diameter, $200 \mu \mathrm{m}$; inner pole diameter, $25 \mu \mathrm{m}$ ) connected to a stimulus isolator (Iso Flex; A.M.P.I.). All stimuli were generated in Matlab.

Because we wanted to quantify the net impact of a connection upon the postsynaptic neuron (i.e., the effect caused on the cortical neuron by a presynaptic spike), we concentrated on analyzing postsynaptic potentials (PSPs) in current-clamp. Stimulation amplitude was determined based on the minimal stimulation approach (Fig. 2A; Raastad et al., 1992; Stratford et al., 1996; Gil et al., 1997, 1999), as follows. We applied single depolarizing square current pulses of $0.1 \mathrm{~ms}$ duration; amplitude was gradually increased until a clear PSP was seen in a fraction of trials. Slightly lowering stimulus amplitude led to complete response failure; slightly increasing amplitude caused an increase in response reliability with no observed change in latency, magnitude, or shape (Fig. $2 A$ ). We set the final magnitude at the latter level, such that response failures to temporally isolated single stimuli were not observed over $\sim 10$ repetitions. This approach ensured that failures of stimulation were negligible while the number of stimulated fibers was kept low (putatively $\sim 1$ ). We did not observe any systematic difference in the occurrence of stimulation failures across depressing or facilitating synapses. In all synapses, fluctuations in success probability were anticorrelated, such that a failure tended to follow a successful synaptic event and vice versa, even at the 
A

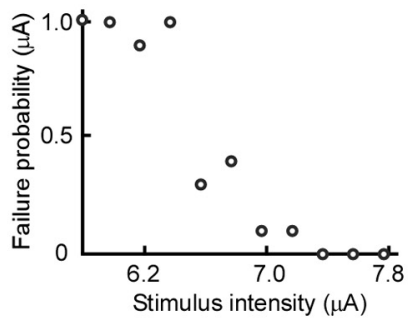

B

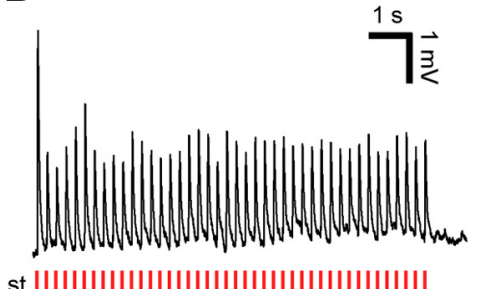

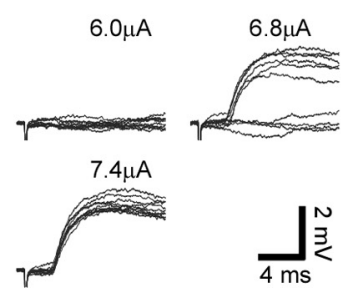

C

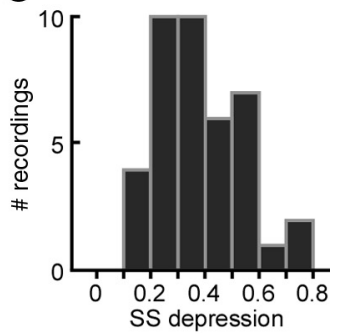

D
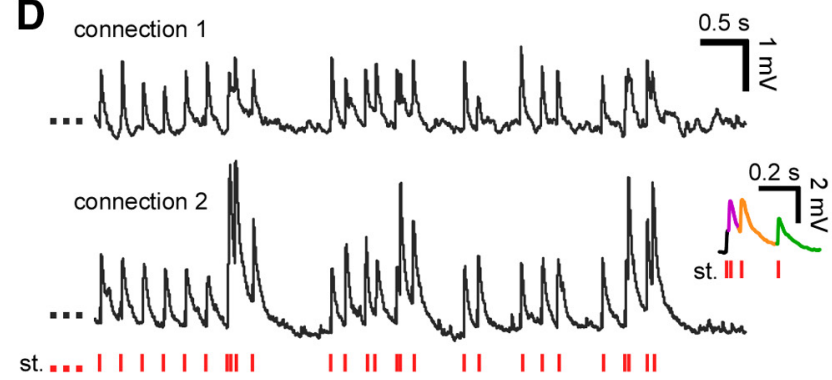

E

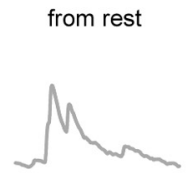

st. II I |
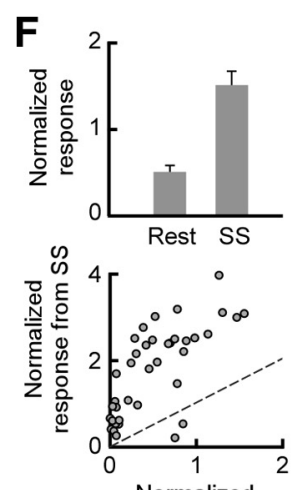

Normalized response from rest

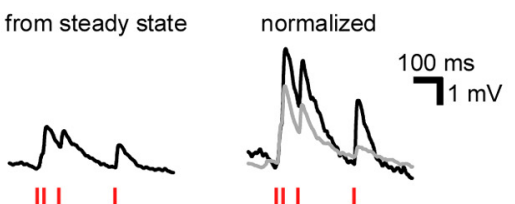

II I I II | ।

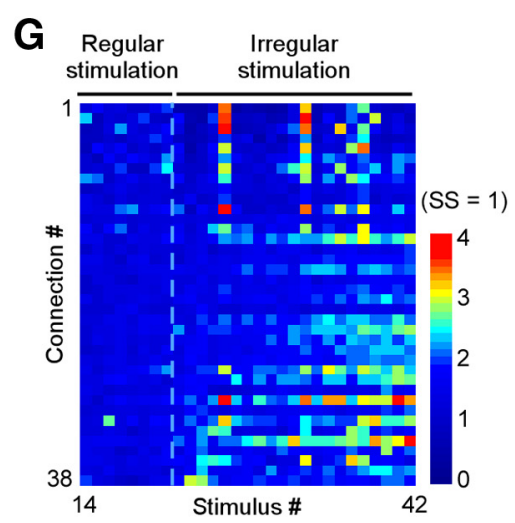

Figure 2. Diverse TC short-term plasticity elicited during ongoing stimulation. $\boldsymbol{A}$, Protocol for setting stimulus amplitude. There was a clear distinction between failed and successful trials (with PSPs evoked at fixed latency). Stimulus amplitude was set at the minimum level that gave no stimulation failures. $\boldsymbol{B}$, Example TC connection depresses under regular stimulation from rest. The stimulus train (st.) is shown at the bottom. C, Depression from rest to steady state (SS), computed for each recording as the ratio of steady-state PSP divided by initial PSP (also termed adaptation ratio), across the population $(n=38)$. $\boldsymbol{D}$, Diverse behavior of two example connections after a switch from steady-state regular stimulation to an irregular train with identical average frequency (stimulation pattern shown at bottom). Inset shows magnified PSPs of connection 2 immediately after switch; different colors correspond to successive PSPs. Both synapses depressed following stimulation from rest. $\boldsymbol{E}$, Responses of one connection to an irregular pattern after switching during ongoing activity, compared with responses of the same

A

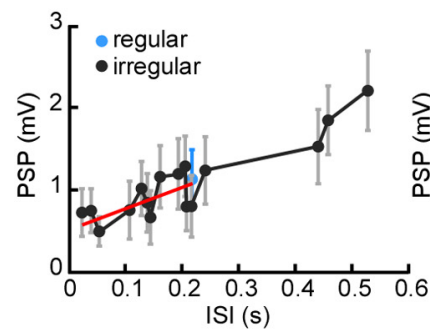

B

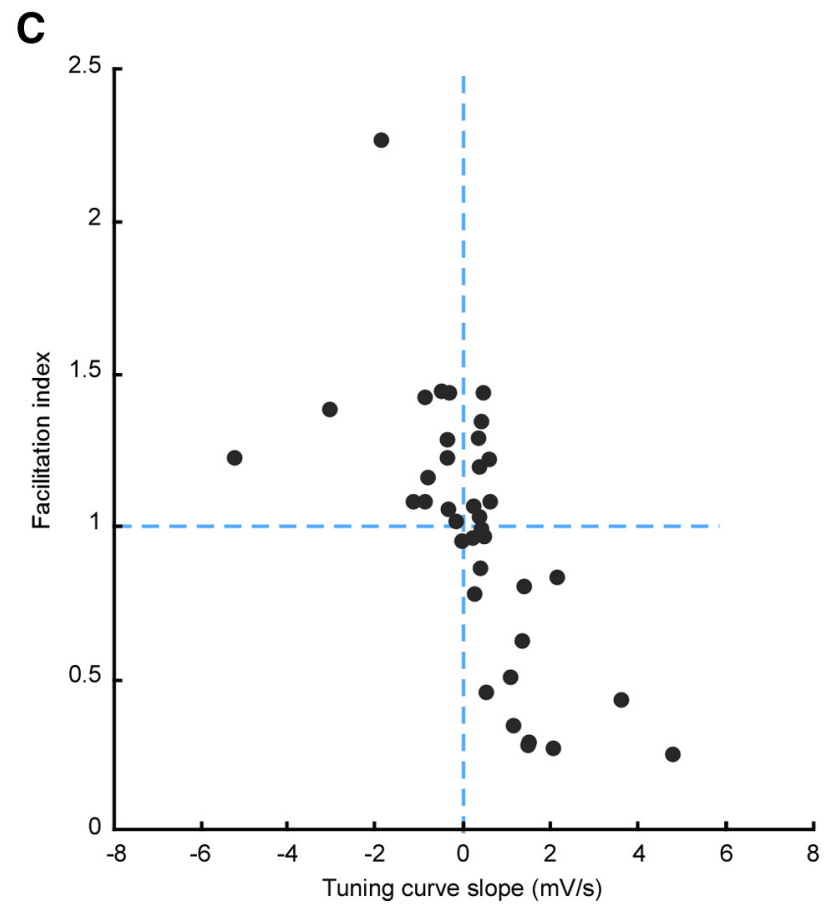

Figure 3. Population analysis of STP diversity. $\boldsymbol{A}$, Tuning curve showing dependence of PSP magnitude on ISI for a connection whose responses are smaller for short ISIs. Black, Responses to irregular stimulus; blue (single data point), responses to regular stimulus; red, linear fit to initial (short-interval) part of tuning curve. Error bars indicate SEM. $\boldsymbol{B}$, Tuning curve for a connection whose responses are larger for short ISIs. Note the similarity of black and blue values in both $\boldsymbol{A}$ and $\boldsymbol{B}$, indicating tuning unaffected by whether the interval is within a regular or irregular train. $\boldsymbol{C}$, Facilitation index (relative response after switch from regular to irregular stimulation) plotted against TCS across the population Index is normalized such that $1=$ no increase compared with steady state.

shortest stimulus intervals. Moreover, any drift in measured success probability during the experiment resulted in the elimination of the recording from the dataset. Stimulus amplitudes were 1-15 $\mu \mathrm{A}$, toward the lower end of previously reported thresholds for TC activation and an order of magnitude lower than thresholds for antidromic activation of

connection to the same pattern initiated from rest (after a pause of $>5 \mathrm{~s}$ ). Normalized, Responses normalized to first PSP peak in the pattern. Response facilitation became evident after prior depression. $\boldsymbol{F}$, Top, Average normalized responses to short pulses in an identical irregular pattern, presented from rest or from steady state. PSP responses to the second and third stimuli in the pattern are averaged together and then normalized to the first PSP peak (as in $\boldsymbol{E}$ ). Error bars indicate SEM ( $n=38)$. Bottom, Scatter plot of normalized responses to short pulses in the same pattern from rest or after steady state (same data as top). Dashed line indicates identity. Prior depression enhanced facilitation. $G$, Diverse plasticity of PSP peaks across different connections. Stimulation was with a 42 -pulse regular-irregular sequence as in $\boldsymbol{D}$; plot begins at stimulus 14 in the sequence, while transition to the irregular train occurs at stimulus 22 (dashed line). Each row represents one connection ( $n=38$ ). For each connection, PSP peak magnitude is normalized to its value at steady state (left side of plot: s.s. $=1$ ). Recordings (rows) are ordered from the smallest (top) to the largest (bottom) relative facilitation after the switch from regular to irregular stimulation. 
A
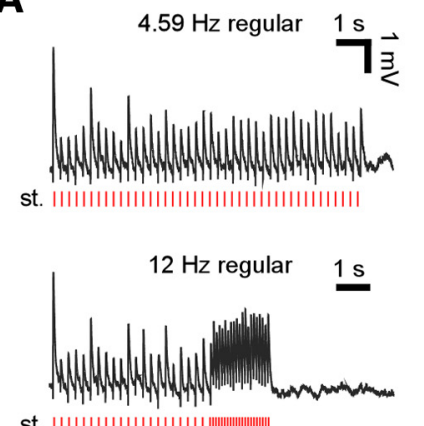
st. IIIIIIIIIIIIIIIIIIIIII |||||||||||||||||||

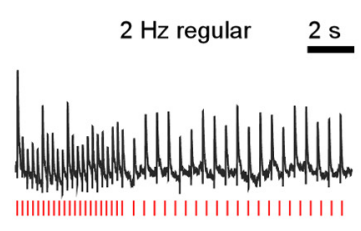

$4.59 \mathrm{~Hz}$ irregular

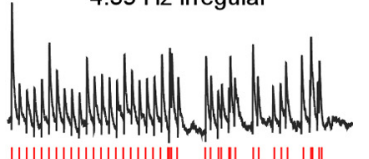

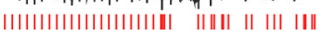
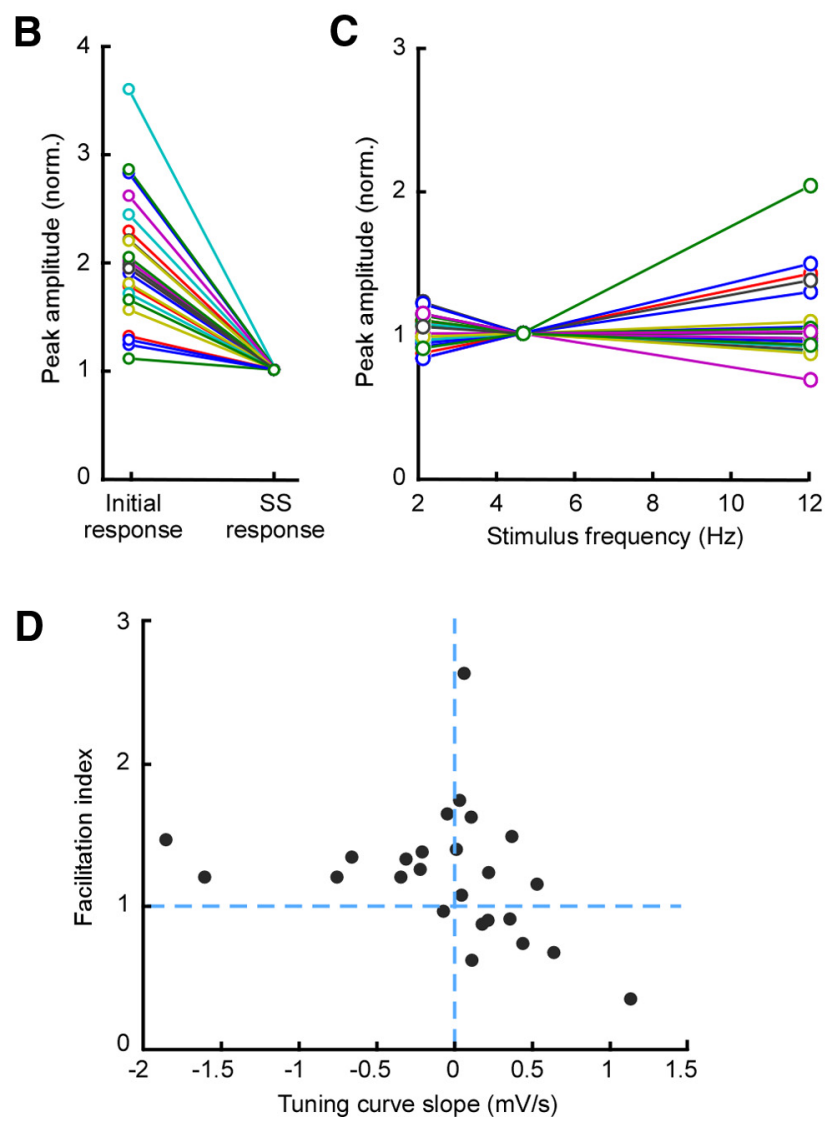

Figure 4. Diversity of STP under regular stimulation. $\boldsymbol{A}$, Example responses to the different forms of stimulus sequence: regular stimulation with or without a switch to a different frequency (indicated above each trace) and regular-irregular stimulation. All responses are from the same recording. Stimulus patterns are shown under each trace. $B$, Comparison of initial and steady-state responses across the population recorded with regular stimulation ( $n=24)$. Each connected pair of points (colored line) corresponds to one recording. For all connections, the response at steady state was smaller than the response from rest. C, Tuning curves for all recordings with regular stimulation at three different frequencies. Responses are normalized to the steady-state value at $4.59 \mathrm{~Hz}$. Tuning was diverse, with a different slope for each neuron. $\boldsymbol{D}$, Facilitation index (i.e., the relative response after the switch from regular to irregular stimulation) plotted against TCS obtained for regular stimulation, for all recordings. norm., Normalized; st., stimulus train; SS, steady state.

corticothalamic neurons (Rose and Metherate, 2001). After setting the stimulus amplitude as above, we checked that repetitive stimulation continued to produce successful responses with unchanging latency and stereotypical shape throughout the train. Response characteristics remained stable over the course of the experiment; otherwise, the recording was discarded.

Stimulation protocols consisted of sequences resulting from the combination of regular and irregular pulse trains. In the main protocol (Fig.

2), a regular train was followed by an irregular train, both with the same average frequency $(4.59 \mathrm{~Hz})$ and duration (21 pulses, $4.36 \mathrm{~s})$. While the regular train had a constant ISI, the irregular train consisted of pulses at different interspersed intervals in the range 13-806 ms. A single specific irregular train was used, extracted from a recording of whisker-evoked action potential activity in the VPM thalamic nucleus of a urethaneanesthetized rat (Petersen et al., 2008). Each sequence ( 9 s long) was repeated 10-15 times per recording; each trial lasted $10 \mathrm{~s}$, including periods of silence during which baseline properties were monitored. Additionally, there was a stimulation pause between trials $5 \mathrm{~s}$ (trial start corresponded to condition "from rest"). A further set of recordings (Fig. 4) used stimulation protocols consisting of sequences of regular stimuli, with a train of 21 pulses at $4.59 \mathrm{~Hz}$ followed either by another train at the same frequency or a train at 2 or $12 \mathrm{~Hz}$. All protocols were applied with the same stimulation intensity, which was determined as described above.

Inhibitory blockade. A set of experiments was performed with the $\mathrm{GABA}_{\mathrm{A}}$ antagonist DNDS added to the recording pipette. To verify the effect of DNDS, we performed separate voltage-clamp experiments and measured the reversal potential of evoked TC synaptic currents $12 \mathrm{~ms}$ after the stimulus (Fig. 5A). In these experiments, TC EPSCs reversed at the glutamatergic reversal potential $(0 \mathrm{mV})$ rather than at the hyperpolarized potential found in the absence of DNDS $(n=3)$. DNDS concentration was $0.5 \mathrm{~mm}(n=16)$ or $1 \mathrm{~mm}(n=9)$ : no effect of varying the concentration was observed ( $p=0.49$, two-dimensional KolmogorovSmirnov test), so experiments with different concentrations were pooled together.

Photostimulation recordings. For recordings involving mapping of synaptic inputs via laser-scanning photostimulation of caged glutamate, standard ACSF was modified with the following concentrations (in mM): 0.2 MNI-caged glutamate (Tocris Bioscience); 0.005 D,L-3[( \pm )-2carboxypiperazine-4-yl]-propyl-1-phosphonic acid, an antagonist of NMDA receptors; $4 \mathrm{CaCl}_{2}$; and $4 \mathrm{MgCl}_{2}$. Recordings were performed at room temperature. Neurons were patched under visual guidance using borosilicate electrodes (4-6 M $\Omega$ ) filled with intracellular solution containing the following (in $\mathrm{mM}$ ): $128 \mathrm{~K}$-methylsulfate, $4 \mathrm{MgCl}_{2}, 10 \mathrm{HEPES}$, 1 EGTA, $4 \mathrm{Na}_{2}$ ATP, $0.4 \mathrm{Na}_{2} \mathrm{GTP}, 10 \mathrm{Na}$-phosphocreatine, and 3 ascorbic acid, $\mathrm{pH}$ 7.25. Recordings were performed in voltage-clamp mode, filtered at $5 \mathrm{kHz}$, and sampled at $10 \mathrm{kHz}$. Cells were clamped at $-70 \mathrm{mV}$, near the reversal potential of inhibitory currents (Bureau et al., 2008), to isolate the excitatory component of synaptic responses. Focal photolysis of caged glutamate was accomplished with a $2 \mathrm{~ms}, 20 \mathrm{~mW}$ pulse of a UV laser (DPSS Lasers) through a $4 \times$ objective. Connections between thalamic neurons and the recorded cell in cortex were detected at sites where stimulation evoked EPSCs. Spiking in thalamic cells occurred only when glutamate was uncaged near their cell bodies, at a mean distance of $\sim 40$ $\mu \mathrm{m}$ from the soma (Bureau et al., 2006). The stimulus pattern consisted of 324 positions on an $18 \times 18$ grid ( $75 \mu \mathrm{m}$ spacing). Software for control and acquisition was written in Matlab (Suter et al., 2010). Synaptic input maps for individual neurons were constructed by computing the mean current amplitude, averaged over a $50 \mathrm{~ms}$ time window beginning $6 \mathrm{~ms}$ after the UV stimulus for each location. These responses were used to build an input map for each cell (Fig. $1 B-D)$.

Histology. A subset of neurons recorded with Alexa Fluor 594 in the patch pipette was histologically processed and recovered. After wholecell recording, the slice was fixed (4\% paraformaldehyde in PBS; $\mathrm{pH} 7.3$ ) at room temperature for $2 \mathrm{~h}$. Slices were then rinsed $3 \times 10 \mathrm{~min}$ in PBS, dried, and coverslipped in a solution of Mowiol (EMD Biosciences) with $N$-propyl gallate. Confocal stacks $\sim 80 \mu \mathrm{m}$ thick were acquired using oil-immersion $20-40 \times$ objectives in an inverted microscope (TCS SL; Leica). Serial optical sections were set at $0.5 \mu \mathrm{m}$ intervals. Images were processed using ImageJ (NIH, http://rsb.info.nih.gov/ij/). Stacks were viewed after maximal projection onto two dimensions.

Analysis. To compute PSP amplitude, we searched for the first membrane potential peak in the window extending from 0.5 to $12 \mathrm{~ms}$ after the stimulation pulse, averaged the membrane potential over five data samples (from -0.1 to $0.1 \mathrm{~ms}$ relative to the raw peak), and subtracted a baseline averaged over $2 \mathrm{~ms}$ immediately preceding the stimulation pulse. This short baseline effectively compensated for depolarization 
A

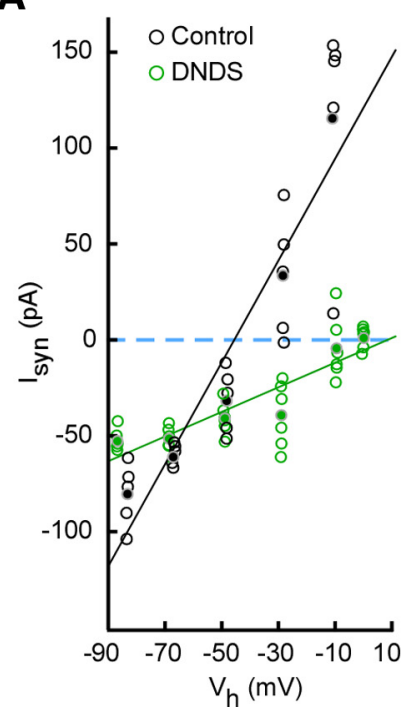

B

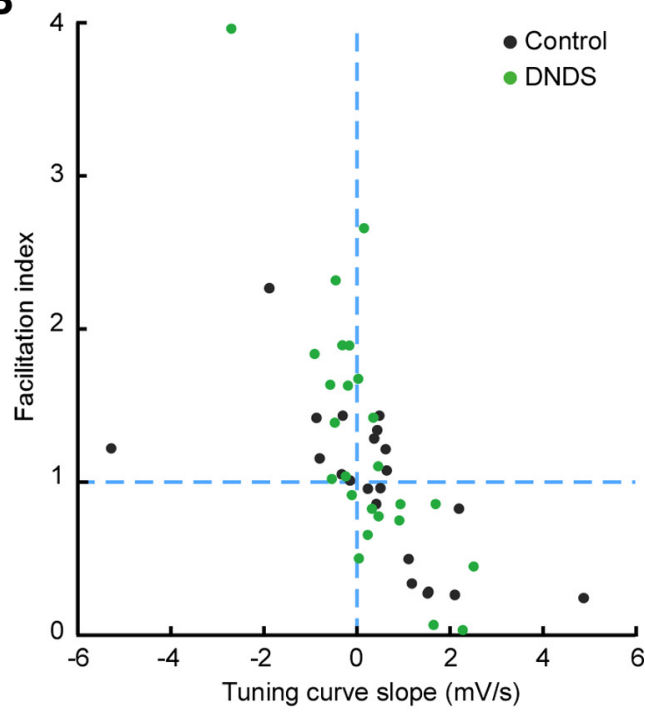

Figure 5. Negligible effect of inhibitory blockade on STP diversity. $A$, Verification of DNDS-mediated block of inhibition. I-V curves constructed from EPSC responses in voltage-clamp from two different neurons in the same slice, without (black) and with (green) DNDS in the internal solution. The slight difference in holding potential $\left(V_{h}\right)$ among points at each nominal holding potential is caused by correction for the voltage drop across the series resistance. Note absence of synaptic response at the reversal potential for excitation $(\sim 0 \mathrm{mV}$ ) with DNDS. $B$, Facilitation index plotted against TCS for experiments with and without DNDS in the recording pipette (control, $n=22 ; \mathrm{DNDS}, n=25$ ). Note the similarity between the two distributions.

A

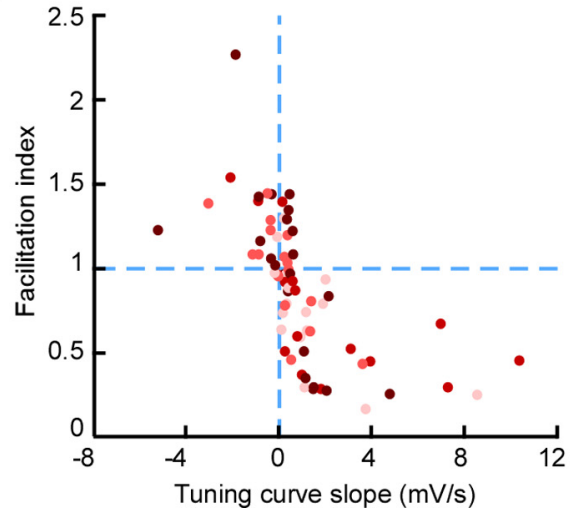

B
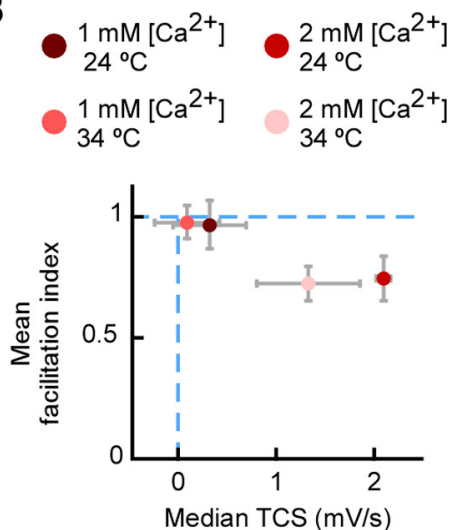

Figure 6. STP diversity across temperatures and extracellular $\left[\mathrm{Ca}^{2+}\right]$. A, Facilitation index plotted against TCS for experiments conducted at different temperatures and extracellular $\left[\mathrm{Ca}^{2+}\right]$ values. Group sizes: $n=22$ for $\left[\mathrm{Ca}^{2+}\right]=1 \mathrm{~mm}$, temperature $=$ $24^{\circ} \mathrm{C} ; n=16$ for $\left[\mathrm{Ca}^{2+}\right]=1 \mathrm{~mm}$, temperature $=32-34^{\circ} \mathrm{C} ; n=16$ for $\left[\mathrm{Ca}^{2+}\right]=2 \mathrm{~mm}$, temperature $=24^{\circ} \mathrm{C} ; n=16$ for $\left[\mathrm{Ca}^{2+}\right]$ $=2 \mathrm{~mm}$, temperature $=32-34^{\circ} \mathrm{C}$. Diversity occurred for all recording conditions. $\boldsymbol{B}$, Central values across groups classified by recording condition. Consistent with a tendency toward depression, the mean facilitation index (post-switch response) was $<1$, and the median TCS was positive (compare with dashed lines). Error bars indicate SEM.

caused by earlier PSPs. Stimulus artifacts were previously removed from the baseline period by median filtering. Mean PSP amplitude was computed for each stimulus in the train.

To compute the steady-state response level, we considered PSPs evoked during regular stimulation. We discarded the first five PSPs (i.e., approximately the first second of stimulation) and computed the mean steady-state PSP amplitude by averaging over all remaining PSPs evoked during regular stimulation. Steady-state depression (Fig. 2C) was evaluated by taking the ratio of the steady-state PSP amplitude to the average PSP amplitude in response to the first pulse in the train (also sometimes referred to as the "adaptation ratio" in the literature). Ratios $<1$ indicated depression. We computed a facilitation index to measure the relative response upon switching from regular to irregular trains during ongoing stimulation, as follows. First, we averaged the PSP amplitudes evoked by the second and third pulses after the switch to irregular stim- ulation, to reduce the dependence on a single, specific interval value. Then, we obtained the facilitation index as the ratio of this quantity to the steady-state PSP amplitude just before the switch.

Tuning curves for each synaptic connection were computed by plotting PSP magnitude as a function of the previous ISI. After constructing the tuning curve for irregular stimulation, a tuning curve slope (TCS; Fig. 3) was fit by linear regression to the initial part of the tuning curve (including only intervals shorter than the regular interval, $218 \mathrm{~ms}$ ), to the late part of the curve (intervals longer than regular), or to the full curve. All three possibilities produced a significant negative correlation between the resulting TCS and the facilitation index (described above), but the fits based on the initial part of the tuning curve gave the tightest empirical correlation. Hence, we present results for the initial (fastest timescale, $<218 \mathrm{~ms}$ ) part of the curve. TCSs for regular stimulation (Fig. 4) were fit by linear regression to the curve from 2 to $12 \mathrm{~Hz}$.

All analyses except for part of the statistical testing were conducted in Matlab (MathWorks). Statistical testing of diversity in the TCS and facilitation index variables across the main dataset was designed as follows. Using restricted maximum likelihood, we fit each variable (TCS, facilitation index) to a linear mixed-effects model with temperature and extracellular $\left[\mathrm{Ca}^{2+}\right]$ as fixed effects and age as a random effect. This analysis was programmed in the $\mathrm{R}$ language. The analysis indicated a significant effect of $\left[\mathrm{Ca}^{2+}\right]$ on TCS $(p=0.018)$, although not on facilitation index $(p=0.085)$. Because of this dependence of TCS on $\left[\mathrm{Ca}^{2+}\right]$, we divided the dataset into a group for each $\left[\mathrm{Ca}^{2+}\right]$ and conducted the remaining nonparametric (Spearman) correlation analyses separately for each group. Results are first presented for the $\left[\mathrm{Ca}^{2+}\right]=1 \mathrm{~mm}$ group (Fig. $3 C$ ), and then compared for different $\left[\mathrm{Ca}^{2+}\right]$ and temperatures (Fig. 6).

\section{Results}

Ongoing stimulation evokes diverse thalamocortical short-term plasticity

To examine the effect of ongoing stimulation of afferent TC synapses, we performed whole-cell patch-clamp recordings of PSPs from visually identified regular spiking neurons located within layer 4 barrels in mouse TC slices (Fig. 1; animals of at least 2 postnatal weeks of age). We focused on PSPs recorded in current-clamp mode, rather than on postsynaptic currents, to quantify the net impact of connections upon the postsynaptic neuron.

We first measured STP evoked by repetitive stimulation begun from rest (Fig. 2). We stimulated TC fibers with an extracellular electrode. To restrict stimulation to a reduced number of fibers (putatively down to a single fiber), we used a protocol adapted from minimal stimulation, setting the stimulus magnitude such that a temporally isolated single stimulus evoked a successful response in the majority of trials, clearly distinguishable from failures (Fig. 2A). We verified that at this stimulation magnitude, successful PSPs maintained their stereotypical shape 
throughout a train of repetitive stimulation, suggesting that the fibers contributing to the response remained stable; stimulation settings are further detailed in the Electrical stimulation section of Materials and Methods. Under these conditions, the distribution of peak amplitudes of PSP responses to temporally isolated stimuli was between $0.70-7.92 \mathrm{mV}$ (median, $2.22 \mathrm{mV}$ ), consistent with earlier in vitro work using minimal stimulation protocols in rat and cat (Stratford et al., 1996; Gil et al., 1999). In the following, "connection" refers to the single fiber or small number of fibers excited by this stimulation protocol.

An example response to a stimulus train started from rest can be seen in Figure $2 B$. In this example, stimulation occurred at regular (periodic) intervals (frequency, $4.59 \mathrm{~Hz}$ ). Under stimulation at this frequency, all connections displayed net depression from rest to steady state (Fig. 2C), consistent with the literature on TC STPs; the exact amount of depression varied from connection to connection. Depression always reached steady state earlier than $1 \mathrm{~s}$ after beginning stimulation, which again is in line with earlier work performed under similar conditions (Gil et al., 1999; Gabernet et al., 2005).

A more surprising behavior occurred when STP was examined during ongoing stimulation, once responses had reached steady state. After several seconds of stimulation, we switched to a stimulus sequence with irregularly spaced intervals but with mean frequency matched to that of the earlier regular sequence (i.e., the average interval was unchanged). This switch in the pattern of ongoing stimulation caused different connections to respond in remarkably different ways (Fig. $2 D)$. The transition from the regular to the irregular pattern-which, notably, interspersed long and short intervals (i.e., low and high instantaneous frequencies)provided evidence that some connections responded more to long intervals and were more depressed after short intervals (Fig. 2D, connection 1), consistent with STP dominated by depression. However, other connections had an enhanced response to short intervals, effectively acting as spike burst detectors (Fig. 2D, connection 2).

We emphasize that these differences in STP between connections during irregular stimulation appeared when stimulating from a predepressed steady state. All connections had previously reached depression upon regular stimulation from rest. This suggested that the facilitated response to short intervals evoked in some connections after switching to irregular stimulation might depend on the fact that the switch occurred upon a background of ongoing stimulation (i.e., prior predepression or conditioning might be required). Indeed, the exact same irregular stimulus stellate neurons $(n=25)$.
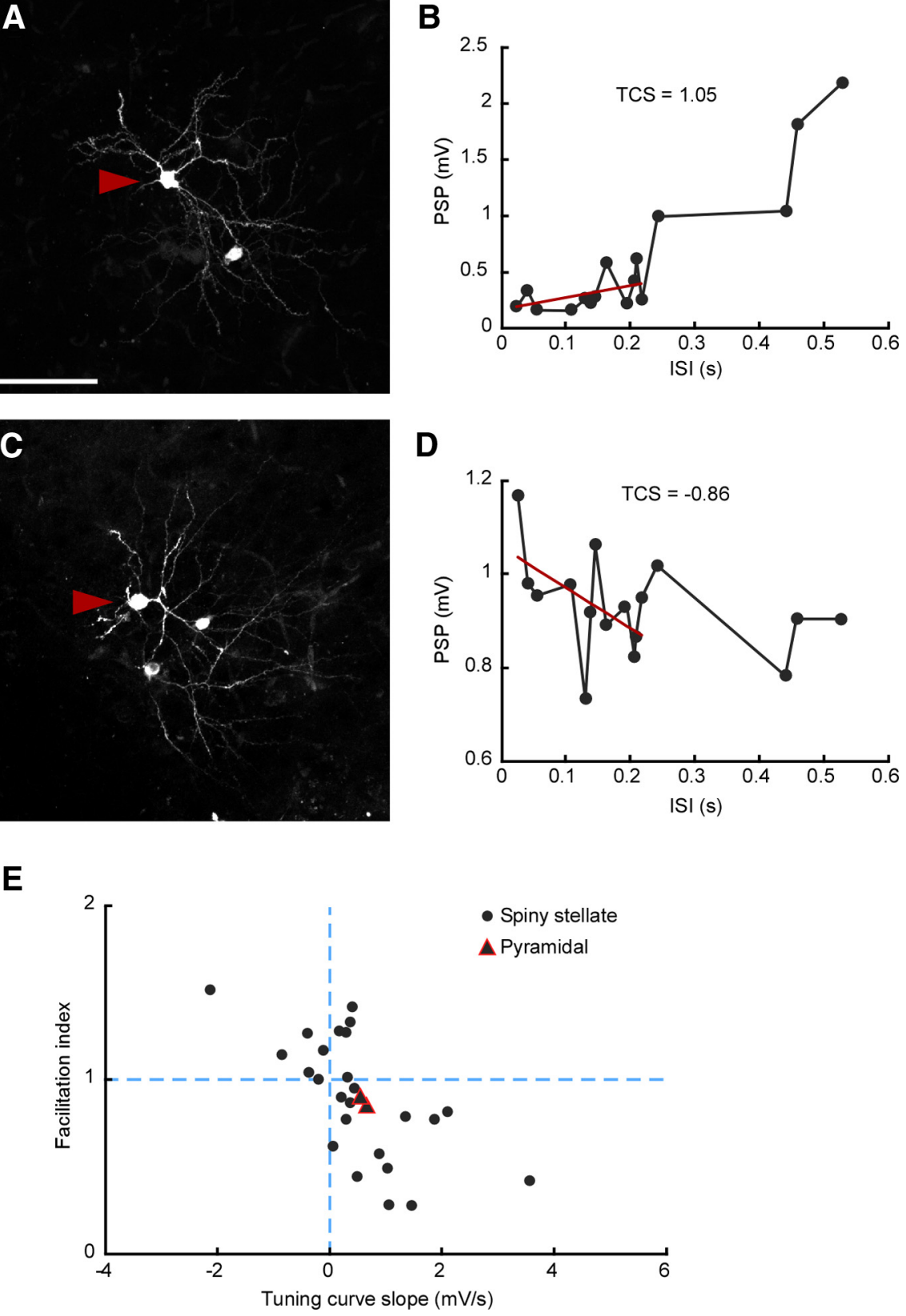

Figure 7. Diverse STP within recovered neurons. $A, C$, Two examples of spiny stellate neurons, fixed, recovered and observed under fluorescent microscopy. Arrowheads indicate somata of recorded neurons. Scale bar, $100 \mu \mathrm{m} . \boldsymbol{B}, \mathbf{D}$, Corresponding ISI tuning curves (black) and TCS (red). E, Facilitation index (i.e., the relative response after the switch from regular to irregular stimulation) plotted against TCS for the subset of recovered neurons. Note the considerable diversity within the population of identified spiny

train presented from rest produced different dynamics compared with when it was presented from steady state, after prior stimulation (Fig. 2E). The relative response to the short intervals in the train (obtained by normalizing to the first response in the train) was much larger after switching from regular to irregular stimulation than after initiating irregular stimulation from rest (Fig. $2 F ; p<7.2 \times 10^{-12}$, paired $t$ test; $n=38$ recordings). Therefore, relative facilitation to short intervals required preconditioning.

To better visualize the range of STP diversity across connections, we plotted the sequence of PSP response peaks for a population of $n=38$ recordings, focusing on responses beginning well into the steady state (starting from stimulus 14 in the train; Fig. $2 G$ ). The plot shows that different connections responded most 

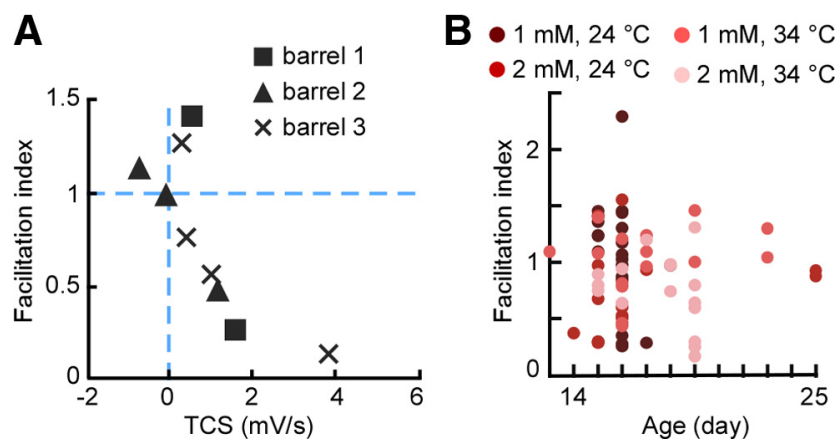

Figure 8. STP diversity across conditions. $\boldsymbol{A}$, Values for three sets of neurons (one quartet, one triplet, and one pair), each recorded within the same barrel in a slice, with the stimulating electrode fixed in position. $\boldsymbol{B}$, Absence of correlation between facilitation index and age. Facilitation index plotted against postnatal age.

strongly at different moments in the irregular stimulation pattern. A few connections even reached their maximum magnitude late in the sequence rather than at the onset of stimulation from rest (data not shown). Thus, TC synaptic populations did not behave with uniform dynamics. Rather, ongoing stimulation brought out STP that was highly heterogeneous across connections: each connection responded preferentially, and therefore contributed most strongly to TC information transfer, at particular times.

\section{STP for each connection is predicted by tuning to the latest interval}

The data presented above establish that each connection responded in a unique manner to irregular stimulation started from steady state. We wondered whether this response was predicted by the tuning of PSP responses to instantaneous ISIs: in other words, whether STP depended only on the most recent activity. Alternatively, the state of STP could depend on contextual, longer-timescale properties of an overall stimulus pattern (e.g., the overall irregular or regular nature of the pattern). To gain insight into this issue, for each connection we constructed a tuning curve by plotting PSP magnitude as a function of the preceding ISI during irregular stimulation (Fig. $3 A, B$ ). We considered only PSPs evoked once steady state was reached, discarding the first few responses from rest (see Materials and Methods). We computed the slope of the tuning curve by linear regression (over the range of intervals up to $218 \mathrm{~ms}$, which gave the best empirical results; Materials and Methods). This TCS provided a simple measure of whether a connection tended to respond more to shorter or to longer ISIs. Connections with smaller responses to short intervals (i.e., to high instantaneous frequencies) had positive TCSs (Fig. 3A), while connections with larger responses to short intervals had negative TCSs (Fig. $3 B$ ). We emphasize that this simple quantification of response tuning disregards effects on timescales longer than a single ISI.

We next computed the normalized response of each connection after switching from regular to irregular stimulation (hereafter referred to as the "facilitation index"). To obtain the facilitation index, we divided the average PSP amplitude evoked for the first two intervals after the switch by the steady-state PSP amplitude just before the switch (Materials and Methods): the index was $<1$ when the mean response amplitude was reduced after the switch and $>1$ when amplitude was increased after the switch.

To compare the behaviors of different connections, we plotted the facilitation index of each connection against its TCS (Fig. 3C).
This plot showed two principal results. First, there was substantial diversity across the population both in the facilitation index and in the TCS. Second, the two quantities had a strong negative correlation (Fig. 3C; Spearman $r=-0.74$; $p<10^{-7}$; $n=38$ ). Because TCS was computed from single-interval PSP tuning curves, this strong negative correlation implies that $r^{2} \sim 55 \%$ of the variation in facilitation index across the population was explained by the dependence of PSP magnitude on the single most recent ISI. Moreover, as mentioned, the single-ISI TCS was computed based on the range of intervals from 0 to $218 \mathrm{~ms}$ (Materials and Methods). Hence, the variability in STP evoked after switching to irregular stimulation could be predicted largely by instantaneous interval-by-interval tuning on a fast timescale of up to $\sim 200$ ms. In sum, despite its simplicity, the single-interval TCS description did a remarkably good job of capturing STP behavior during ongoing stimulation across the population.

\section{STP diversity occurs under regular and irregular stimulation}

The wide range of intervals present in irregular stimulus trains helped to bring out the diversity of STP: each connection responded preferentially to a particular subset of intervals within an irregular train (Fig. 3). However, this did not imply that irregular stimulation is required to trigger diverse STP. We hypothesized that, instead, diversity might also emerge during ongoing regular stimulation at different frequencies. To test this, we performed a new set of experiments where the first part of the stimulus train, which elicited initial depression from rest, had the same frequency as before $(4.59 \mathrm{~Hz})$, but the second part of the train was a regular sequence at either the same frequency $(4.59 \mathrm{~Hz})$ or at a lower or higher frequency $(2$ or $12 \mathrm{~Hz}$ ). Thus, at a certain time after the first part of the stimulus train, stimulation frequency could increase, decrease, or remain unchanged (Fig. 4A).

As expected from the earlier dataset (Fig. 2C), all connections in the new experiments were depressed from stimulus onset to steady state (Fig. 4B). Once depression to steady state was complete and the switch to the second part of the stimulus train occurred, connections displayed variable tuning. Some connections responded more strongly to long intervals (lower frequency), while others responded more to shorter intervals (higher frequency; Fig. 4C). This suggested that tuning curves constructed under regular stimulation might also capture STP diversity. To verify this, in each of the new experiments we measured responses to trials where we switched from regular to irregular stimulation, and computed the corresponding facilitation index, as described above. We then plotted the facilitation index of each connection (computed for irregular stimulation) against its TCS (computed from the tuning curve to regular stimulation; Fig. 4D). The correlation between facilitation index and regular TCS was strong (Spearman $r=-0.48 ; p=0.019 ; n=24$ ). Thus, the diverse STP demonstrated by irregular stimulation also occurred during regular stimulation, and behavior during regular stimulation could predict behavior under irregular stimulation (Kandaswamy et al., 2010). Moreover, responses to a given interval under irregular stimulation matched those under regular stimulation (Fig. $3 A, B$, black and blue plots), suggesting that tuning was little affected by the regular or irregular context.

That responses during irregular stimulation were predicted by tuning to regular stimulation supports the notion that STP behavior during ongoing stimulation was largely governed by mechanisms acting on the timescale of a single ISI, rather than by mechanisms dependent on longer timescales (e.g., the overall regular or irregular nature of the stimulus pattern). As a consequence, characterizing STP did not require a larger set of stimulus 
protocols (e.g., reproducing the exact sequences of presynaptic activation that each connection undergoes in vivo).

\section{STP diversity has a monosynaptic locus}

To narrow down the phenomena underlying STP diversity, we examined whether STP during ongoing stimulation correlated with other properties of synaptic responses. As above, for this analysis we used the facilitation index as the measure for STP. We first considered whether the facilitation index was related to the initial PSP magnitude. Interestingly, these quantities had a significant negative correlation both when the computation was performed across all trials (Spearman $r=-0.44 ; p=0.006 ; n=38$ ) and after excluding trials where there was a response failure on the first stimulus (Spearman $r=-0.52 ; p=0.00086 ; n=38$ ). Next, we assessed whether the facilitation index correlated with the amount of depression from rest to steady state (i.e., with the magnitude of the steady-state response ratio; Fig. 2C). The greater the facilitation index for ongoing stimulation, the stronger the depressed steady-state response (i.e., the weaker the depression for stimulation from rest; Spearman $r=0.34 ; p=0.037$; $n=38$ ). These results indicate that the mechanisms regulating the tendencies of synapses to depress or facilitate were active both when stimulating from rest and during ongoing stimulation, yet initially were occluded by the dominant initial depression affecting all synapses.

A contributor to STP diversity could be effective facilitation arising from increased postsynaptic summation caused by broader PSPs. For example, PSP width could differ across recordings as a result of variation in intrinsic membrane properties, which would be expected to influence PSP width throughout the train. Another mechanism for broadened PSPs could be shortterm depression of disynaptic inhibition: this would imply increased PSP broadening, and summation, over the course of a stimulus train (Gabernet et al., 2005; Higley and Contreras, 2006). To cover both of these possibilities and to test for an effect of PSP width, PSP broadening, and summation, we measured PSP width as the full-width at half-maximum, both for the first response from rest and the first response after switching to irregular stimulation from steady state. We found no correlation of facilitation index with PSP width either for the first response from rest (Spearman $r=-0.011 ; p=0.95 ; n=41$ ) or for the first response after switching (Spearman $r=$ $-0.056 ; p=0.73 ; n=41)$. Thus, differences in summation caused by variation in PSP width were not involved in STP diversity during ongoing stimulation.

We next considered the possibility that STP diversity could result from differences in the moment-to-moment balance of excitatory and inhibitory contributions to the PSP. This could occur as follows. In addition to monosynaptic excitation, the TC pathway generates powerful disynaptic inhibition that shapes the net effect of thalamic activation upon the target cortical cell (Agmon and Connors, 1991; Porter et al., 2001; Gabernet et al., 2005; Sun et al., 2006; Cruikshank et al., 2007). We reasoned that STP diversity might be caused by differences in the rate of depression of the disynaptic inhibitory component of PSPs relative to the monosynaptic excitatory component (Beierlein et al., 2003; Gabernet et al., 2005; Higley and Contreras, 2006; Heiss et al., 2008). For example, a net facilitating PSP might be produced by a strongly depressing inhibitory component, rather than by a facilitating excitatory component.

To examine this possibility, we conducted a set of experiments with the intracellular $\mathrm{GABA}_{\mathrm{A}}$ antagonist DNDS, a chloride channel blocker, added to the patch pipette (Dudek and Friedlander,
1996; Covic and Sherman, 2011). DNDS eliminated the inhibitory contribution to synaptic responses (Fig. 5A; Materials and Methods). STP remained diverse across the set of experiments with DNDS: the distributions of facilitation index and TCS were consistent with the null hypothesis of no difference to those of experiments with intact inhibition (Fig. $5 B ; p=0.34$, twodimensional Kolmogorov-Smirnov two-sample test; $n=25$ for DNDS, $n=22$ for controls). We conclude that the observed STP diversity of TC synapses during ongoing stimulation was caused by differences in the properties of monosynaptic excitatory connections.

\section{STP dependence occurs across temperatures and extracellular $\left[\mathrm{Ca}^{2+}\right]$ levels}

To gain further insight into the mechanisms underlying STP diversity, we examined the effects of temperature and extracellular $\left[\mathrm{Ca}^{2+}\right]$. We performed recordings at room temperature $\left(24^{\circ} \mathrm{C}\right)$ and $32-34^{\circ} \mathrm{C}$, and at two different $\left[\mathrm{Ca}^{2+}\right]$ values: one typical of slice experiments $\left(\left[\mathrm{Ca}^{2+}\right]=2 \mathrm{mM}\right)$ and one closer to physiological values, used for all the experiments described up to this point $\left(\left[\mathrm{Ca}^{2+}\right]=1 \mathrm{mM}\right)$. STP was diverse for all four groups (Fig. $6 \mathrm{~A}$, see group sizes). Extracellular $\left[\mathrm{Ca}^{2+}\right]$ influenced STP, because there was less depression at $1 \mathrm{~mm}$ than at $2 \mathrm{~mm}$ (Fig. 6A; dependence of TCS on $\left[\mathrm{Ca}^{2+}\right], p=0.018$; linear mixed-effects model, Materials and Methods). There was no significant difference between data at different temperatures (Fig. 6; $p=0.85$ for dependence of TCS, $p=0.999$ for dependence of facilitation index). Thus, $\left[\mathrm{Ca}^{2+}\right]$ (but not temperature) had a significant influence on STP during ongoing stimulation, but there was also strong STP diversity within recordings at each $\left[\mathrm{Ca}^{2+}\right]$ level.

Given the difference between data at different $\left[\mathrm{Ca}^{2+}\right]$ values, for further analysis we separated the recordings into subgroups for $\left[\mathrm{Ca}^{2+}\right]=1 \mathrm{mM}$ and $\left[\mathrm{Ca}^{2+}\right]=2 \mathrm{mM}$. In both subgroups, STP was heterogeneous yet tended toward depression on average: the mean facilitation index was $<1$ or close to 1 (Fig. $6 B ; 0.969$ for $\left[\mathrm{Ca}^{2+}\right]=1 \mathrm{mM}, n=38 ; 0.735$ for $\left.\left[\mathrm{Ca}^{2+}\right]=2 \mathrm{mM}, n=32\right)$, and the median TCS was positive (Fig. $6 B ; 0.314$ for $\left[\mathrm{Ca}^{2+}\right]=1 \mathrm{mM}$; 0.692 for $\left[\mathrm{Ca}^{2+}\right]=2 \mathrm{mM}$ ). Thus, the average STP of TC connections tended toward depression regardless of experimental condition.

\section{STP diversity occurs within a single category of TC connections onto spiny stellate neurons}

We wondered whether synapses with more or less facilitation constitute separate categories or a continuum. Separate categories of STP, if present, could correspond to connections originating from different subpathways within the whisker system (for review, see Diamond et al., 2008). No separate categories (distinct clusters or "clouds") were visually evident in the data (Fig. 3C). However, we examined the possibility more closely using several lines of analysis.

First, while all our recordings were from layer 4 regular spiking neurons located within visually identified barrels, we recovered a subset of neurons histologically $(n=27)$ and found that all were either spiny stellate $(n=25)$ or star pyramidal cells $(n=2$; Fig. 7). Diversity of STP held specifically across the set of identified spiny stellate neurons (Fig. 7), confirming that STP was heterogeneous within the population of thalamic connections onto the main class of thalamorecipient layer 4 neurons. Second, the diversity of STP held even for different neurons recorded within the same barrel and slice, and with the stimulating electrode fixed in the same location (Fig. 8A). Third, diversity could not be explained by the fact that experiments spanned a range of ages, as 


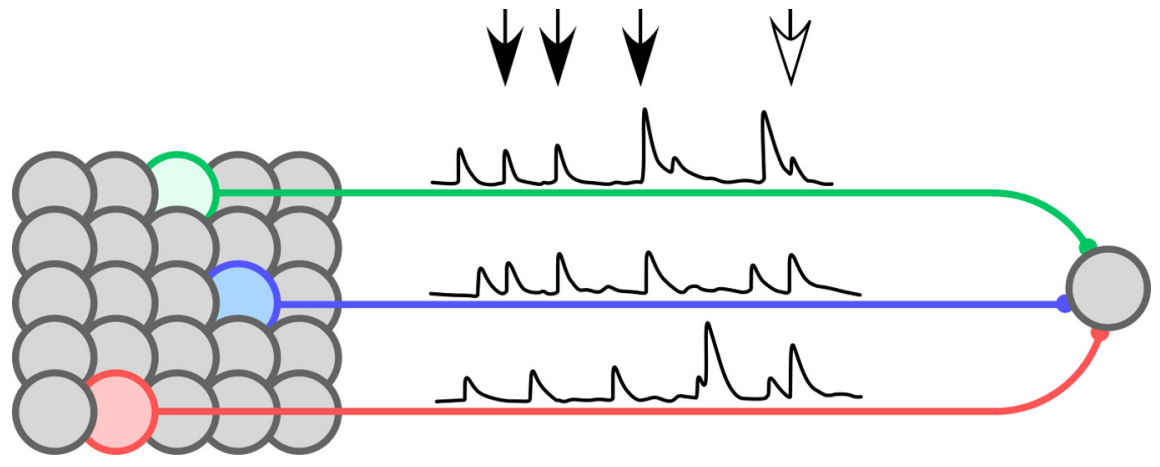

Figure 9. STP diversity can enrich information transmission in the TC pathway. The schematic shows different TC neurons within a VPM population (at left). These can encode distinct stimulus features and therefore respond at different times (reflected in the trains of PSPs corresponding to synaptic inputs from the three colored neurons). The green and blue neurons encode similar stimulus features and tend to respond in greater synchrony, while the red neuron tends to respond at different times. All three connect to a cortical neuron, at right. At certain moments, TC connections from both the green and blue neurons are strong enough to permit the downstream cell to selectively detect synchrony across those neurons (black arrows). Information about the value of the stimulus features encoded by the green and blue neurons is specifically transmitted at those times. However, at other moments differences in STP across the connections (the connection from the green neuron depresses more than the blue), combined with slight differences in spike timing, can lead to a switch in the subset of neurons whose partial synchrony can be detected: now, the subset includes either the green or the blue neuron together with others. For example, the white arrow indicates a time when the green, blue, and red neurons fire together but only the blue and red connections are strong enough to affect the activation of the downstream cell. At this time, it is the value of the features encoded by the blue and red neurons that is transmitted.

STP did not depend on postnatal age ( $p=0.73$ for effect on TCS; $p=0.76$ for effect on relative post-switch response; linear mixedeffects model; Fig. 8B).

In summary, these data are consistent with the existence of a continuum of STP diversity within the population of lemniscal TC inputs, and specifically within inputs onto spiny stellate neurons.

\section{Discussion}

TC synapses are commonly treated as a uniform population with homogeneous STP. Our results reveal that lemniscal TC connections respond with diverse STP when new stimuli arrive against a background of ongoing activity. These data indicate a continuum of STP behaviors within monosynaptic TC connections onto spiny stellate neurons. This implies that the dynamic behavior of TC synapses as a population is not well described by the mean of the population. Moreover, the effectiveness of an individual TC connection is not well described by a single static "weight" in response to a temporally isolated stimulus: its short-term dynamic behavior must be considered as well (Buonomano and Maass, 2009).

Our data show that STP variability is a monosynaptic property. The overall tendency toward short-term facilitation or depression during ongoing stimulation varied with extracellular $\left[\mathrm{Ca}^{2+}\right]$, suggesting dependence on presynaptic mechanisms (Fig. 6). Moreover, response facilitation was apparent only after "predepression" (i.e., after the dominant depression component observed from rest had reached steady state; Fig. 2E-G; Galarreta and Hestrin, 2000; Beck et al., 2005; Müller et al., 2010). This behavior cannot be explained by models of synaptic dynamics based on uniform resource depletion; rather, additional mechanisms are required (Beck et al., 2005; Kandaswamy et al., 2010; Müller et al., 2010). Preliminary work suggests that classic multiple-component models (Abbott et al., 1997; Tsodyks and Markram, 1997; Varela et al., 1997; Markram et al., 1998; Kandaswamy et al., 2010) can capture the STP diversity measured during ongoing stimulation, while an additional component is necessary to fit the dominant depression occurring from rest
(H. Kato, C. Mirasso, and M. Maravall, unpublished observations).

Our results indicate that TC shortterm dynamics tend toward depression on average. First, all connections were depressed by stimulation from rest (Fig. $2 B, C)$. Second, after a switch to irregular stimulation containing shorter intervals, responses were reduced on average, regardless of temperature and $\left[\mathrm{Ca}^{2+}\right]$ (Fig. $6 B$ ). Finally, the median TCS was positive (i.e., with greater depression at shorter intervals; Fig. 6B). This overall behavior agrees with earlier findings that the average TC connection does not facilitate (Stratford et al., 1996) and that shortterm depression tends to dominate when synapses are pooled together (Swadlow et al., 2002; Stoelzel et al., 2009). While consistent with these results, our data reveal important diversity around the average behavior.

\section{Experimental considerations}

Layer 4 neurons receive collateral inputs from corticothalamic neurons in layer 6, which can be antidromically activated by thalamic stimulation and evoke longer-latency, facilitating responses (Ferster and Lindström, 1985; White and Keller, 1987; Staiger et al., 1996; Stratford et al., 1996; Zhang and Deschênes, 1997; Rose and Metherate, 2001; Beierlein et al., 2003). We wondered whether facilitating PSPs in our data corresponded to corticothalamic axons. However, we found no significant difference in response latency between depressing and facilitating connections (data not shown); neither did connections cluster into separate categories, as expected for TC versus corticothalamic responses (Fig. 3C; Beierlein et al., 2003). Moreover, we used only stimulus amplitudes at the lower end of published TC activation thresholds, an order of magnitude lower than thresholds for corticothalamic activation (Materials and Methods; Rose and Metherate, 2001). This makes it unlikely that our data were contaminated by corticothalamic responses.

While our protocol was designed to stimulate only one or a reduced number of fibers, it is conceivable that repetitive stimulation, especially after short intervals, could recruit additional fibers and lead to apparent response facilitation occurring differentially in different synapses. Several arguments indicate a negligible effect of this confound. First, PSP shape was maintained stereotypically during the stimulus train. Second, responses of connections to short intervals facilitated much more weakly during stimulation from rest than during ongoing stimulation, even when the stimulation patterns were identical and thus equally likely to recruit additional fibers (Fig. $2 E-G$ ). Third, a tuning curve with the appearance of facilitation but caused by multiplefiber recruitment would look like a depressing (positive TCS) tuning curve but with a stepwise increase added on for the shortest intervals, because the effect of recruiting additional fibers would be a sudden enhancement of the response at those intervals. Conversely, we found that facilitating STP correlated with tuning curves whose overall slope was negative (Figs. 3C, 6). Fourth, facilitating tuning curves were present under regular stimulation (Fig. 4C), not just under irregular stimulation, which had a greater presence of short intervals that could potentially 
enhance recruitment. Importantly, tuning curves constructed from regular stimulation predicted responses to irregular stimulation (Fig. 4D).

It is possible that we inadvertently stimulated multiple fibers instead of single fibers throughout the train. If so, this caused an underestimation of STP diversity, as each measured response pooled (and therefore averaged) the behavior of several single synapses. In sum, the observed presence of facilitating synapses cannot be explained by additional recruitment of TC axons at higher frequencies or inadvertent stimulation of multiple fibers.

\section{STP diversity in neural pathways}

STP diversity also exists in other synaptic pathways. Different components of STP cause depression or facilitation acting over various timescales (Zucker and Regehr, 2002). Each class of synapse expresses a distinct combination of components, resulting in a characteristic net STP (Dittman et al., 2000), which is dependent both on presynaptic and postsynaptic neuron type (Thomson, 1997; Markram et al., 1998; Reyes et al., 1998; Thomson and Lamy, 2007; Williams and Atkinson, 2007). However, significant variability can occur within each class (Rosenmund et al., 1993; Dobrunz and Stevens, 1997; Murthy et al., 1997; Losonczy et al., 2002). STP can even differ across connections made by one neuron onto several postsynaptic neurons of a single type (Markram et al., 1998). In some populations, STP variability tends to cluster according to the postsynaptic cell, suggesting regulation of plasticity at the single-cell level (Yang and Xu-Friedman, 2012). Moreover, synaptic dynamics confer particular temporal filtering properties to each postsynaptic neuron: different neurons have distinct tuning to interspike intervals (Carlson, 2009; George et al., 2011). The present study is, to our knowledge, the first characterization of STP diversity in a TC pathway, where it can have profound consequences for sensory coding at the population level.

\section{Functional implications}

One consequence of our findings follows from the "predepressed" condition of TC synapses during activated states (Castro-Alamancos and Oldford, 2002; Castro-Alamancos, 2004; Boudreau and Ferster, 2005). This condition appears to be caused by prior activity rather than state-dependent modulation and may be comparable to the steady state reported here (Stoelzel et al., 2009). Hence, the onset of whisker sensory input while in the predepressed condition may be similar to the switch to irregular stimulation in our main protocol (Fig. 2). Our results suggest that the subset of TC synapses with greater facilitation could act as privileged channels for detecting such sudden stimulus changes.

That a given temporal stimulus pattern facilitates some synapses while depressing others implies a second consequence for sensory coding: different TC synapses are strong at distinct times during ongoing activity (Fig. $2 G$ ). The subset of synapses providing the strongest sensory input will vary from moment to moment, directing information selectively (Buonomano and Merzenich, 1995; Buonomano et al., 1997; Buonomano, 2000; Buonomano and Maass, 2009). Different TC synapses provide distinct sensory messages, because different VPM neurons encode different stimulus properties (e.g., whisker velocity or whisker acceleration; Petersen et al., 2008). Consequently, at one moment the TC connection contributing the strongest weight to a cortical neuron could originate, for example, from a VPM cell representing whisker velocity, while at another moment the main contributor could represent acceleration (Fig. 9).
Neurons are sensitive detectors of small changes in synchrony across their afferent population (Rossant et al., 2011; Brette, 2012). STP diversity could refine this capacity by focusing the selectivity of a postsynaptic neuron for partial synchrony onto the group of inputs whose connections are currently strongest. This is particularly relevant for the transfer of sensory information from VPM to cortex, because VPM populations display stimulusdependent changes in synchrony (Temereanca et al., 2008). Since VPM neurons encode distinct stimulus features (Petersen et al., 2008), different groups of neurons become coactivated at different times, depending on the patterns present in the stimulus (Bale et al., 2011). Changes in synchrony therefore contribute to sensory encoding. STP diversity could help thalamorecipient cells focus on detecting differential synchrony within the subset of afferents that projects strong inputs at a given time (Fig. 9).

\section{Cell-level regulation of STP}

Our data indicate that TC synapses could constitute different information channels (Fig. 2G). It is possible that STP is specifically regulated at the presynaptic or postsynaptic cell level. If, for example, STP properties cluster presynaptically, all TC synapses projecting from a particular neuron will have similar dynamics. STP could also cluster postsynaptically (Yang and Xu-Friedman, 2012), rendering each cortical neuron sensitive to specific intervals. Whether STP is regulated on a cell-to-cell basis is an important issue for future exploration. In any case, the STP expressed by any synapse is likely to depend on its history of usage and thus be specific to some extent (Sippy et al., 2003; Cheetham et al., 2007; Branco et al., 2008; Pfister et al., 2010; Carvalho and Buonomano, 2011; Yang and Xu-Friedman, 2012).

\section{References}

Abbott LF, Regehr WG (2004) Synaptic computation. Nature 431:796-803. CrossRef Medline

Abbott LF, Varela JA, Sen K, Nelson SB (1997) Synaptic depression and cortical gain control. Science 275:220-224. Medline

Agmon A, Connors BW (1991) Thalamocortical responses of mouse somatosensory (barrel) cortex in vitro. Neuroscience 41:365-379. CrossRef Medline

Arabzadeh E, Zorzin E, Diamond ME (2005) Neuronal encoding of texture in the whisker sensory pathway. PLoS Biol 3:e17. CrossRef Medline

Bale MR, Ince RAA, Santagata G, Petersen RS (2011) Population coding of texture-induced whisker motion in the ventroposterior medial nucleus of the thalamus. Soc Neurosci Abstr 37:704.14.

Beck O, Chistiakova M, Obermayer K, Volgushev M (2005) Adaptation at synaptic connections to layer $2 / 3$ pyramidal cells in rat visual cortex. J Neurophysiol 94:363-376. CrossRef Medline

Beierlein M, Gibson JR, Connors BW (2003) Two dynamically distinct inhibitory networks in layer 4 of the neocortex. J Neurophysiol 90:29873000. CrossRef Medline

Borgdorff AJ, Poulet JF, Petersen CC (2007) Facilitating sensory responses in developing mouse somatosensory barrel cortex. J Neurophysiol 97 : 2992-3003. CrossRef Medline

Boudreau CE, Ferster D (2005) Short-term depression in thalamocortical synapses of cat primary visual cortex. J Neurosci 25:7179-7190. CrossRef Medline

Branco T, Staras K, Darcy KJ, Goda Y (2008) Local dendritic activity sets release probability at hippocampal synapses. Neuron 59:475-485. CrossRef Medline

Brette R (2012) Computing with neural synchrony. PLoS Comput Biol 8:e1002561. CrossRef Medline

Bruno RM, Sakmann B (2006) Cortex is driven by weak but synchronously active thalamocortical synapses. Science 312:1622-1627. CrossRef Medline

Buonomano DV (2000) Decoding temporal information: a model based on short-term synaptic plasticity. J Neurosci 20:1129-1141. Medline

Buonomano DV, Maass W (2009) State-dependent computations: spatio- 
temporal processing in cortical networks. Nat Rev Neurosci 10:113-125. CrossRef Medline

Buonomano DV, Merzenich MM (1995) Temporal information transformed into a spatial code by a neural network with realistic properties. Science 267:1028-1030. CrossRef Medline

Buonomano DV, Hickmott PW, Merzenich MM (1997) Context-sensitive synaptic plasticity and temporal-to-spatial transformations in hippocampal slices. Proc Natl Acad Sci U S A 94:10403-10408. CrossRef Medline

Bureau I, von Saint Paul F, Svoboda K (2006) Interdigitated paralemniscal and lemniscal pathways in the mouse barrel cortex. PLoS Biol 4:e382. CrossRef Medline

Bureau I, Shepherd GM, Svoboda K (2008) Circuit and plasticity defects in the developing somatosensory cortex of FMR1 knock-out mice. J Neurosci 28:5178-5188. CrossRef Medline

Carlson BA (2009) Temporal-pattern recognition by single neurons in a sensory pathway devoted to social communication behavior. J Neurosci 29:9417-9428. CrossRef Medline

Carvalho TP, Buonomano DV (2011) A novel learning rule for long-term plasticity of short-term synaptic plasticity enhances temporal processing. Front Integr Neurosci 5:20. CrossRef Medline

Castro-Alamancos MA (2004) Absence of rapid sensory adaptation in neocortex during information processing states. Neuron 41:455-464. CrossRef Medline

Castro-Alamancos MA, Oldford E (2002) Cortical sensory suppression during arousal is due to the activity-dependent depression of thalamocortical synapses. J Physiol 541:319-331. CrossRef Medline

Cheetham CE, Hammond MS, Edwards CE, Finnerty GT (2007) Sensory experience alters cortical connectivity and synaptic function site specifically. J Neurosci 27:3456-3465. CrossRef Medline

Chung S, Li X, Nelson SB (2002) Short-term depression at thalamocortical synapses contributes to rapid adaptation of cortical sensory responses in vivo. Neuron 34:437-446. CrossRef Medline

Covic EN, Sherman SM (2011) Synaptic properties of connections between the primary and secondary auditory cortices in mice. Cereb Cortex 21: 2425-2441. CrossRef Medline

Crair MC, Malenka RC (1995) A critical period for long-term potentiation at thalamocortical synapses. Nature 375:325-328. CrossRef Medline

Cruikshank SJ, Lewis TJ, Connors BW (2007) Synaptic basis for intense thalamocortical activation of feedforward inhibitory cells in neocortex. Nat Neurosci 10:462-468. CrossRef Medline

Diamond ME, von Heimendahl M, Knutsen PM, Kleinfeld D, Ahissar E (2008) "Where" and "what" in the whisker sensorimotor system. Nat Rev Neurosci 9:601-612. CrossRef Medline

Díaz-Quesada M, Maravall M (2008) Intrinsic mechanisms for adaptive gain rescaling in barrel cortex. J Neurosci 28:696-710. CrossRef Medline

Dittman JS, Kreitzer AC, Regehr WG (2000) Interplay between facilitation, depression, and residual calcium at three presynaptic terminals. J Neurosci 20:1374-1385. Medline

Dobrunz LE, Stevens CF (1997) Heterogeneity of release probability, facilitation, and depletion at central synapses. Neuron 18:995-1008. CrossRef Medline

Dudek SM, Friedlander MJ (1996) Intracellular blockade of inhibitory synaptic responses in visual cortical layer IV neurons. J Neurophysiol 75: 2167-2173. Medline

Ferster D, Lindström S (1985) Synaptic excitation of neurones in area 17 of the cat by intracortical axon collaterals of cortico-geniculate cells. J Physiol 367:233-252. Medline

Fortune ES, Rose GJ (2001) Short-term synaptic plasticity as a temporal filter. Trends Neurosci 24:381-385. CrossRef Medline

Gabernet L, Jadhav SP, Feldman DE, Carandini M, Scanziani M (2005) Somatosensory integration controlled by dynamic thalamocortical feedforward inhibition. Neuron 48:315-327. CrossRef Medline

Galarreta M, Hestrin S (2000) Burst firing induces a rebound of synaptic strength at unitary neocortical synapses. J Neurophysiol 83:621-624. Medline

George AA, Lyons-Warren AM, Ma X, Carlson BA (2011) A diversity of synaptic filters are created by temporal summation of excitation and inhibition. J Neurosci 31:14721-14734. CrossRef Medline

Gil Z, Connors BW, Amitai Y (1997) Differential regulation of neocortical synapses by neuromodulators and activity. Neuron 19:679-686. CrossRef Medline

Gil Z, Connors BW, Amitai Y (1999) Efficacy of thalamocortical and intra- cortical synaptic connections: quanta, innervation, and reliability. Neuron 23:385-397. CrossRef Medline

Heiss JE, Katz Y, Ganmor E, Lampl I (2008) Shift in the balance between excitation and inhibition during sensory adaptation of S1 neurons. J Neurosci 28:13320-13330. CrossRef Medline

Higley MJ, Contreras D (2006) Balanced excitation and inhibition determine spike timing during frequency adaptation. J Neurosci 26:448-457. CrossRef Medline

Jadhav SP, Feldman DE (2010) Texture coding in the whisker system. Curr Opin Neurobiol 20:313-318. CrossRef Medline

Jadhav SP, Wolfe J, Feldman DE (2009) Sparse temporal coding of elementary tactile features during active whisker sensation. Nat Neurosci 12:792800. CrossRef Medline

Kandaswamy U, Deng PY, Stevens CF, Klyachko VA (2010) The role of presynaptic dynamics in processing of natural spike trains in hippocampal synapses. J Neurosci 30:15904-15914. CrossRef Medline

Lak A, Arabzadeh E, Diamond ME (2008) Enhanced response of neurons in rat somatosensory cortex to stimuli containing temporal noise. Cereb Cortex 18:1085-1093. CrossRef Medline

Lak A, Arabzadeh E, Harris JA, Diamond ME (2010) Correlated physiological and perceptual effects of noise in a tactile stimulus. Proc Natl Acad Sci U S A 107:7981-7986. CrossRef Medline

Losonczy A, Zhang L, Shigemoto R, Somogyi P, Nusser Z (2002) Cell type dependence and variability in the short-term plasticity of EPSCs in identified mouse hippocampal interneurones. J Physiol 542:193-210. CrossRef Medline

Lottem E, Azouz R (2008) Dynamic translation of surface coarseness into whisker vibrations. J Neurophysiol 100:2852-2865. CrossRef Medline

Lottem E, Azouz R (2009) Mechanisms of tactile information transmission through whisker vibrations. J Neurosci 29:11686-11697. CrossRef Medline

Markram H, Wang Y, Tsodyks M (1998) Differential signaling via the same axon of neocortical pyramidal neurons. Proc Natl Acad Sci U S A 95: 5323-5328. CrossRef Medline

McCormick DA, Connors BW, Lighthall JW, Prince DA (1985) Comparative electrophysiology of pyramidal and sparsely spiny stellate neurons of the neocortex. J Neurophysiol 54:782-806. Medline

Morita T, Kang H, Wolfe J, Jadhav SP, Feldman DE (2011) Psychometric curve and behavioral strategies for whisker-based texture discrimination in rats. PLoS One 6:e20437. CrossRef Medline

Müller M, Goutman JD, Kochubey O, Schneggenburger R (2010) Interaction between facilitation and depression at a large CNS synapse reveals mechanisms of short-term plasticity. J Neurosci 30:2007-2016. CrossRef Medline

Murthy VN, Sejnowski TJ, Stevens CF (1997) Heterogeneous release properties of visualized individual hippocampal synapses. Neuron 18:599_ 612. CrossRef Medline

Petersen CC (2007) The functional organization of the barrel cortex. Neuron 56:339-355. CrossRef Medline

Petersen RS, Brambilla M, Bale MR, Alenda A, Panzeri S, Montemurro MA, Maravall M (2008) Diverse and temporally precise kinetic feature selectivity in the VPm thalamic nucleus. Neuron 60:890-903. CrossRef Medline

Pfister JP, Dayan P, Lengyel M (2010) Synapses with short-term plasticity are optimal estimators of presynaptic membrane potentials. Nat Neurosci 13:1271-1275. CrossRef Medline

Pologruto TA, Sabatini BL, Svoboda K (2003) ScanImage: flexible software for operating laser scanning microscopes. Biomed Eng Online 2:13. CrossRef Medline

Porter JT, Johnson CK, Agmon A (2001) Diverse types of interneurons generate thalamus-evoked feedforward inhibition in the mouse barrel cortex. J Neurosci 21:2699-2710. Medline

Raastad M, Storm JF, Andersen P (1992) Putative single quantum and single fibre excitatory postsynaptic currents show similar amplitude range and variability in rat hippocampal slices. Eur J Neurosci 4:113-117. CrossRef Medline

Reig R, Gallego R, Nowak LG, Sanchez-Vives MV (2006) Impact of cortical network activity on short-term synaptic depression. Cereb Cortex 16: 688-695. CrossRef Medline

Reyes A, Lujan R, Rozov A, Burnashev N, Somogyi P, Sakmann B (1998) Target-cell-specific facilitation and depression in neocortical circuits. Nat Neurosci 1:279-285. CrossRef Medline 
Ritt JT, Andermann ML, Moore CI (2008) Embodied information processing: vibrissa mechanics and texture features shape micromotions in actively sensing rats. Neuron 57:599-613. CrossRef Medline

Rose HJ, Metherate R (2001) Thalamic stimulation largely elicits orthodromic, rather than antidromic, cortical activation in an auditory thalamocortical slice. Neuroscience 106:331-340. CrossRef Medline

Rosenmund C, Clements JD, Westbrook GL (1993) Nonuniform probability of glutamate release at a hippocampal synapse. Science 262:754-757. CrossRef Medline

Rossant C, Leijon S, Magnusson AK, Brette R (2011) Sensitivity of noisy neurons to coincident inputs. J Neurosci 31:17193-17206. CrossRef Medline

Sherman SM, Guillery RW (2006) Exploring the thalamus and its role in cortical function. Cambridge, MA: MIT.

Sippy T, Cruz-Martín A, Jeromin A, Schweizer FE (2003) Acute changes in short-term plasticity at synapses with elevated levels of neuronal calcium sensor-1. Nat Neurosci 6:1031-1038. CrossRef Medline

Staiger JF, Zilles K, Freund TF (1996) Recurrent axon collaterals of corticothalamic projection neurons in rat primary somatosensory cortex contribute to excitatory and inhibitory feedback-loops. Anat Embryol (Berl) 194:533-543. Medline

Stoelzel CR, Bereshpolova Y, Swadlow HA (2009) Stability of thalamocortical synaptic transmission across awake brain states. J Neurosci 29:68516859. CrossRef Medline

Stratford KJ, Tarczy-Hornoch K, Martin KA, Bannister NJ, Jack JJ (1996) Excitatory synaptic inputs to spiny stellate cells in cat visual cortex. Nature 382:258-261. CrossRef Medline

Sun QQ, Huguenard JR, Prince DA (2006) Barrel cortex microcircuits: thalamocortical feedforward inhibition in spiny stellate cells is mediated by a small number of fast-spiking interneurons. J Neurosci 26:1219-1230. CrossRef Medline

Suter BA, O'Connor T, Iyer V, Petreanu LT, Hooks BM, Kiritani T, Svoboda K, Shepherd GM (2010) Ephus: multipurpose data acquisition software for neuroscience experiments. Front Neural Circuits 4:100. CrossRef Medline
Swadlow HA, Gusev AG, Bezdudnaya T (2002) Activation of a cortical column by a thalamocortical impulse. J Neurosci 22:7766-7773. Medline

Temereanca S, Brown EN, Simons DJ (2008) Rapid changes in thalamic firing synchrony during repetitive whisker stimulation. J Neurosci 28 : 11153-11164. CrossRef Medline

Thomson AM (1997) Activity-dependent properties of synaptic transmission at two classes of connections made by rat neocortical pyramidal axons in vitro. J Physiol 502:131-147. CrossRef Medline

Thomson AM, Lamy C (2007) Functional maps of neocortical local circuitry. Front Neurosci 1:19-42. CrossRef Medline

Tsodyks MV, Markram H (1997) The neural code between neocortical pyramidal neurons depends on neurotransmitter release probability. Proc Natl Acad Sci U S A 94:719-723. CrossRef Medline

Varela JA, Sen K, Gibson J, Fost J, Abbott LF, Nelson SB (1997) A quantitative description of short-term plasticity at excitatory synapses in layer $2 / 3$ of rat primary visual cortex. J Neurosci 17:7926-7940. Medline

White EL, Keller A (1987) Intrinsic circuitry involving the local axon collaterals of corticothalamic projection cells in mouse SmI cortex. J Comp Neurol 262:13-26. CrossRef Medline

Williams SR, Atkinson SE (2007) Pathway-specific use-dependent dynamics of excitatory synaptic transmission in rat intracortical circuits. J Physiol 585:759-777. CrossRef Medline

Wolfe J, Hill DN, Pahlavan S, Drew PJ, Kleinfeld D, Feldman DE (2008) Texture coding in the rat whisker system: slip-stick versus differential resonance. PLoS Biol 6:e215. CrossRef Medline

Yang H, Xu-Friedman MA (2012) Emergence of coordinated plasticity in the cochlear nucleus and cerebellum. J Neurosci 32:7862-7868. CrossRef Medline

Zhang ZW, Deschênes M (1997) Intracortical axonal projections of lamina VI cells of the primary somatosensory cortex in the rat: a single-cell labeling study. J Neurosci 17:6365-6379. Medline

Zucker RS, Regehr WG (2002) Short-term synaptic plasticity. Annu Rev Physiol 64:355-405. CrossRef Medline 